\title{
Correction to: Lebanese People Living with HIV: Psychiatric Co-morbidities and Psycho-Social Environment
}

\author{
Sandra Abou Kassm ${ }^{1,7}$ (D) Wadih Naja ${ }^{1} \cdot$ Ramzi Haddad $^{1} \cdot$ Rafic Baddoura $^{2} \cdot$ Bernadette Mdawar $^{3} \cdot$ Nour Riachy $^{4}$. \\ Salwa Azar ${ }^{5}$. Carmen Zrour ${ }^{1}$. Jacques Mokhbat ${ }^{6}$
}

Published online: 17 June 2021

(c) Springer Science+Business Media, LLC, part of Springer Nature 2021

Correction to: Community Mental Health Journal https://doi.org/10.1007/s10597-021-00834-5

The original version of this article unfortunately contained a typo in all author names.

The given name and family name of all the authors are swapped and published incorrectly. Now, the correct author names are presented in this correction article.

The original article has been corrected.

Publisher's Note Springer Nature remains neutral with regard to jurisdictional claims in published maps and institutional affiliations.

The original article can be found online at https://doi.org/10.1007/ s10597-021-00834-5.

Sandra Abou Kassm

sandra_akassm@hotmail.com

1 Psychiatry Department, Faculty of Medical Sciences,

Lebanese University, Beirut, Lebanon

2 Rheumatology Department, Faculty of Medical Sciences, Saint Joseph University, Beirut, Lebanon

3 Psychiatry Department, Faculty of Medical Sciences, American University of Beirut, Beirut, Lebanon

4 Pediatrics Department, Faculty of Medical Sciences, Lebanese University, Beirut, Lebanon

5 Internal Medicine Department, Faculty of Medical Sciences, Lebanese University, Beirut, Lebanon

6 Internal Medicine Department, Faculty of Medical Sciences, Lebanese American University, Beirut, Lebanon

7 Mount Lebanon Hospital, Blvd. Camille Chamoun, Hazmieh, P.O. Box: 470, Beirut, Lebanon 